\title{
Investigating the possibility of using recycled magazine paper in the production of newsprint with the aim of proper management of paper waste
}

Seyedeh Fateme Shahcheragh ( $\nabla$ shahcheragh.sfateme@gmail.com )

Islamic Azad University (Tehran North Branch)

Research

Keywords: recycling, waste magazine paper, deinking, CMP, bleaching, newsprint

Posted Date: September 2nd, 2021

DOl: https://doi.org/10.21203/rs.3.rs-772062/v1

License: (c) (1) This work is licensed under a Creative Commons Attribution 4.0 International License.

Read Full License 


\section{Abstract}

In recent yr. due to reduced ligneous resources, increased demand for paper products, increased environmental concerns that are made from virgin papers production, and high volume of waste papers, the need for recycling of papers is felt more than ever. One of the important steps in the process of recycling paper is the deinking of waste papers. The purpose of this study is the deinking of the old magazine papers in order to produce newsprint. In the review, old magazine papers were deinked by Flotation method using: Sodium hydroxide (1\%), Sodium silicate (2\%), Hydrogen peroxide (1\%), and DTPA (1\%). Then they were bleached with an amount of Hydrogen peroxide (1/5\%). 60 grams of paper was made under standard conditions for testing. Then the brightness of handmade papers was measured in three replicates. The result showed that the brightness of non-deinked papers was about $40 \%$, after deinking it was about $50 \%$, and after bleaching it was increased to about $60 \%$. Results indicate that the use of Hydrogen peroxide and its derivatives in bleaching of waste papers are resulted in increasing brightness in several percent. By combining pulp prepared from recycled magazine paper with CMP pulp prepared from a broadleaf species, the results showed that the addition of deinked OMG significantly reduced the brightness of the control sample. Also, adding deinked magazine paper in any proportion to the mixture of imported CMP pulp and long fiber pulp (by increasing the opacity) improves the quality of the printed paper obtained. This recycled paper can be used in production papers that are used temporary and do not need high resistance (such as newsprints).

\section{Introduction}

\subsection{State the problem and purpose}

In recent yr. with the increasing reduction of forest resources worldwide, the reuse of waste paper and their recycling as one of the methods of supplying suitable cellulosic raw materials for the paper industry has received serious attention. In recent yr. international researchers have turned their attention to optimization and finding new ways to remove pollutants, especially ink of waste paper. [8]

In order to meet the consumption of paper within the country, especially newspaper and magazine papers in recent yr. in addition to domestic production, these products are mainly supplied by increasing imports. Due to the high cost of paper imports, efforts have been made to address shortages as much as possible by increasing domestic production. One of the methods of supplying cellulosic raw materials suitable for the paper industry, which has received serious attention worldwide in recent yr. is the recycling of waste paper. Recycling reduces cutting trees. Waste paper is a universal commodity and is a vital raw material for the production of paper and cardboard. As many believe, waste paper recycling is not a new activity, but an expanding one. Inkjet technology has developed tremendously over the last 20 year. and has recovered large amounts of paper waste. Conventional methods of de-inking are currently the methods of washing, flotation, rinsing and flotation in combination, enzymatic, nitrogen, ultrasonic, etc. Among these methods, flotation is more applicable to newsprint. More than $90 \%$ of recycled newspaper paper is deinking using flotation. By recycling one ton of waste paper, 17 large trees can be cut down. Burying 700 
tons of paper is equivalent to cutting 3 hectares of forest per day. The majority of newsprint manufacturers that use recycled fibers for this purpose are located in areas with limited potential for cellulosic resources. [15]

Deinking is considered as a complementary step in waste paper recycling technology, during which by removing printing inks and other materials in waste paper such as adhesives, binders, plastics, etc., which at this stage are considered as pollutants, fibers Recycled cellulose is obtained in a relatively pure form and free of interfering materials for reuse in paper making. In fact, it can be said that the development and improvement of degreasing methods has been one of the important factors in increasing the consumption of recycled paper worldwide. [10] Deinking is done by washing, flotation, chemical and enzymatic deinking methods. The efficiency of deinking by washing method depends on the size of the ink particles and the thickness of the fiber felt layer. The efficiency of the washing step depends on the type of equipment, the nature and the quality of the paper and is usually in the range of $75-90 \%$. Effective bleaching occurs when the ink particle size is between 10-15 microns, while the ink particles are more efficiently removed between $0.5-5$ microns. The washing method is suitable for removing particles of offset and letterpress printing ink that are well dispersed. Flotation is a chemical-mechanical process in which, after injecting air into the flotation cells, air bubbles adhere to the hydrophobic particles of the ink and leave the system after being transferred to the flotation cell surface. In enzymatic degreasing, enzymes attack the ink itself or the surface of the fibers, and the main mechanism of this action is based on loosening the connections between the ink particles and the fibers and removing fine particles. The use of enzymes increases the percentage of pollutants released and the efficiency of the deinking process. [11]

\subsection{Literature Review}

Obradovic and Narayan Mishra (2020) in an article entitled" Mechanical Properties of Recycled Paper and Cardboard" stated, In flotation deinking, the released ink should also be detached from the substrate and dispersed in order to avoid redeposition. However, in flotation deinking the probability of removal of an ink containing particle is driven by a combination of size and surface energy. In flotation deinking a certain amount of agglomera tion is preferable as the removal in flotation deinking is dependent on the size of the particle. The optimum size range is often stated to be between 50 and 150 micrometers. Size alone however is not additionally the agglomerates should emonstrate surface energy prop erties that are more hydrophobic than wash deinking in order to allow for stable attachme nt and transport by air bubbles. The presence of surfactant in the formulation has a hig her value for the result. [4]

Narayan Panda and Kumar Biswal (2020) in an article in "International Journal of Recent Technology and Engineering (IJRTE) ISSN: 2277-3878, Volume-8 Issue-5, January 2020" stated that Sustainable development is always being a key challenge for the human race and treated as the highest priority across the globe. Achieving this goal, mainly depends on the way we deal with our environmental resources. Recycling of paper, which is environmentally healthy and ecofriendly practice contributes to 
waste management, thus leading to efficient use of natural resources. In India, to fulfill the demand of paper consumption for every individual, recycling of waste paper must be triggered. The present research work highlights a comparative study of different chemicals available as surfactants in deinking process. The removal selectivity of ink in DAF (diffused air flotation) cell is effective. In this process, removal of ash, long and short fibers are minimum. Because of hydrophobic nature of ink in the froth, ink particles get separated. Visual assessment of the hand sheet surface images revealed that brightness in \% ISO increased to a higher value for Sodium dodecyl benzene sulfonate as compared to other two surfactants used in this study. The physical properties like tear, tensile strength, double folding is maximum for Sodium dodecyl benzene sulfonate. [13]

Pourmousa (2016) in an article entitle" Effect of Dispersion and Flotation Sequence on Optical and Mechanical Properties of Deinked Computer Printout" stated The effects of dispersion and flotation deinking sequences on the optical and mechanical properties of recycled computer printout deinked pulp were studied. To find the optimized conditions for providing a deinked pulp with higher brightness, preliminary tests were designed and run at three stages with different ratios of fatty acid and surfactant. Deinking with $1 \%$ fatty acid and $0.4 \%$ surfactant was found to be the optimum conditions based on statistical analysis. According to the results the brightness of deinked pulp obtained by dispersion and flotation sequences was $11.8 \%$ ISO higher than that of undeinked pulp. It was found that a dispersion stage with $30 \%$ consistency and at $75^{\circ} \mathrm{C}$, performed before flotation stage, considerably increased the efficiency of flotation through reducing the amount of ink specks in deinked pulp and increasing the pulp brightness by $5.4 \%$ ISO. Despite the loss of mechanical strength, the resultant deinked pulp is appropriate for producing high-quality papers.[9]

Sharifi Taskooh et al. (2015) In an article entitled "Improving the appearance and strength characteristics of sanitary papers by optimizing the variables of the deinking process of deinked recycled pulp (a case study of Latif Paper Products Company)" stated that due to the increasing reduction of forest resources worldwide and increasing environmental pressures, the use of recycled fibers has become a constant part of the raw material for the production of paper products. On the other hand, the use of recycled fibers is associated with a decrease in product quality, which requires further study to increase the quality and quantity of the product. The effect of these factors on the degree of clarity of dry tensile strength index, wet tensile strength index and burst resistance index was investigated. The results were evaluated in the form of CCD ink design and modeled and analyzed by RSM response surface method and the optimal point of the process in different amounts of hydrogen peroxide, sodium hydroxide and sodium silicate is $55.1 \%$ of the bleaching time $90 \mathrm{~min}$, the bleaching temperature is $83^{\circ} \mathrm{C}$ and The final $\mathrm{pH}$ was 5.8. [12]

Husovska (2013) in Western Michigan University in thesis entitled "Investigation of Recycled Paper Deinking Mechanisms, stated that the use of water-based inks is on the rise. Sub-micron pigment particles are used for flexographic and inkjet water-based inks. Conventional deinking eliminates larger particles than those from these new ink systems. Therefore, water-based inks represent recycling difficulty. Deinking experiments of water-based inks are carried out. The deinking strategy initially investigated elimination of pressure sensitive adhesive due to similar acrylic polymer chemistry used in 
water based inks. The impact of $\mathrm{pH}$ on stickies and ink agglomeration during deinking is studied. Experiments in acidic regions show growth of acrylic inks and stickies agglomerates, simplifying elimination. Pre-recycling of water-based inks is explored. Exceptional cleanliness of acidic circuit waters compared to alkaline is demonstrated. Conventional wisdom claims an alkaline environment is needed for ink detachment from paper. It is found that the benefit of acidic milieu is the agglomeration of the pigment - resin complex of water-based ink. Further, flotation deinking of model Inks is performed. Agglomeration and flotation of inkjet inks using surfactants is performed to better understand ink behavior during deinking while limiting its re-deposition. [14]. Ariaie monfared et al. (2011) in an article entitled Enzymatic deinking of office waste paper in comparison with conventional chemical methods: Part One - Appearance and optical properties of paper pulp in 2011 stated that mixed waste office papers is a great source of quality fibers that are processed Non-contact printing has been done on them. Recycling of these papers using conventional chemical deinking process is difficult from technically and economically. In this study, enzymatic deinking was performed as an alternative to conventional chemical deinking. Samples of office waste paper after printing by Xerox using commercial cellulase enzyme derived from Aspergillus niger fungus at three levels of $0.025,0.05$ and $0.1 \%$ based on dry weight of pulp (respectively, equivalent to 25,50 and 100 units, per gram of dry weight of pulp) in two time levels of 10 and $15 \mathrm{~min}$ at $50^{\circ} \mathrm{C}$. The effect of process variables on the appearance and optical properties of desiccated handmade papers was studied. Summarizing the results showed that a treatment in which $0.05 \%$ of enzyme and time of 15 min was used, had the best results and improved the appearance of handmade papers compared to control samples. [2]. Akbarpour et al. in 2010 in an article entitled Investigation of waste paper deinking capability of waste newspaper, in research on waste paper deinking ability by conventional chemical method and the effect of using washing processes, flotation separately and in combination on The optical and visual characteristics of the manufactured papers were investigated. The results obtained from measuring the optical and visual properties of the manufactured papers showed that with 20 min of chemical treatment and the use of a washing step, the maximum degree of brightness was $50.9 \%$ ISO, the minimum degree of yellowness was $14.8 \%$ ISO, the degree of opacity $97.6 \%$ ISO, 507 composite particle number and $2205.5 \mathrm{~mm} 2$ / m2 composite surface area are obtained. When only the flotation process was used for deinking, the opacity improved to $99 \%$ ISO, but the resulting papers had a lower degree of brightness and a higher degree of yellowing of the number and surface area of the composite particles. Also, the results obtained from measuring the number and surface of composite particles on both the mesh and paper sides showed that the paper mesh side has more composite particles and less composite particle surface. According to the evidence obtained from the optical and visual properties of papers made from deinking of waste newspaper papers, using the washing process in the stage of separation of ink particles is more effective and efficient, and the resulting papers have more desirable optical and visual properties. [1]

Kapania et al. (2008) examined the quality of inkjet waste paper by bleaching with peroxide. The results of experiments showed that hydrogen peroxide is effective in increasing the quality by using suitable activating compounds and other peroxy compounds such as peracetic acid in decolorizing waste ink pulp 
paper. The use of hydrogen peroxide and peroxy derivatives in deinking waste paper has increased the brightness by several percent. [6]

Ferguson (2000) investigated the properties of waste paper and compared it with first-hand hardwood pulp and concluded that the recycled paper was a competitor to hardwood pulp and could be used in the production of printing papers. And used writing, sanitary and color paper. [5]. Brian and Felgner (1989) in Paper Engineering Senior Theses entitled "An Analysis of the Wash and Flotation Deinking Processes" stated that, a $40 \%$ addition of fresh pulp to wash and floatation-deinked pulps was sufficient to produce a sheet of similar characteristics as one made from unprinted recycled paper. The only significant difference between the deinked and unprinted sheets was a slight loss of. burst strength. However, a significant difference in strength and opacity characteristics was found when comparing floatation to wash deinked pulps. Mullen, tensile and opacity were higher for floatation deinked pulps. This is due to the fines loss in the wash deinking process. The cost of floatation deinking was found to be slightly higher than wash deinking. However, the yield of $86 \%$ for the floatation process in this procedure is lower than yields generally found in industrial practice. The use of a secondary floatation cell to recapture lost fiber may have increased the yield, thus reducing the cost. It should be noted that the floatation process is very sensitive to upset. Variations in chemical addition. temperature and $\mathrm{pH}$ to name a few, greatly affect the performance of the process. The wash deinking process has fewer process limiting factors. [3]

Les1ie and Turai in AN OVERVIEW of DEINKING OF WASTEPAPER in 1982 stated, more than half of the wastepaper co11ected for recycling is printed; therefore, most of it requires deinking. The deinking process is classified into two main categories: (1) chemical deinking and (2) ultrasonic deinking. Both deinking processes, in turn, are subdivided into two systems: deinking by washing and deinking by flotation. A large majority of the United States and Canadian deinking installations use the deinking by washing method, while in Europe and Japan the deinking by flotation method is preferred [7]. According to the review of numerous articles in the field of waste paper deinking, the purpose of this study is to deink waste magazine papers to produce newspaper paper.

\section{Materials And Methods}

Deinking of the prepared pulp samples was performed using flotation method, which is the most suitable method for separating printed inks by non-contact method. A flotation cell was used for this purpose. The major part of the deinking paper process (separation of the physical bond between the ink particles and the fibers) takes place in the re-pulping stage and inside the pulping machine (Table 1). 
Table 1

Factors and conditions of chemical re-pulping.

\begin{tabular}{|llll|}
\hline Material Type & Quantity (\%) & Conditions & Quantity \\
\hline Sodium hydroxide & $1 \%$ & dry matter $(\%)$ & 8 \\
\hline Hydrogen peroxide & $1 \%$ & temperature $\left({ }^{\circ} \mathrm{C}\right)$ & 50 \\
\hline Sodium silicate & $2 \%$ & time $(\mathrm{min})$ & 20 \\
\hline Polysorbate & $0.2 \%$ & $\mathrm{PH}$ & 11 \\
\hline Calcium chloride & $0.33 \%$ & Mechanical action & Manual stirring \\
\hline DTPA & $0.02 \%$ & Sample dry weight & $160 \mathrm{~g}$ \\
\hline
\end{tabular}

In the flotation stage, using only the foaming agent in the dilute suspension of the pulp and the air entering it, the ink particles separated from the fibers, adhere to the air bubbles and are transferred to the liquid surface, and de-inking operations are completed. In this study, polylobate 80 and calcium chloride were used as foaming agents. Other fixed conditions in the flotation stage have been described in Table 2 .

Table 2

Flotation conditions.

\begin{tabular}{|ll|}
\hline Amount & terms \\
\hline Drought percentage (\%) & 0.8 \\
\hline Temperature (Celsius) & $50-55$ \\
\hline Time (min) & 20 \\
\hline PH & 8 \\
\hline Capacity of the device (liters) & 20 \\
\hline Stirring speed (rpm) & 1300 \\
\hline Air flow rate (liters per min) & 6 \\
\hline
\end{tabular}

At the end of the flotation step, the fiber suspension was drained from the cell. Then, the deinked samples of the magazine were decolorized one step with hydrogen peroxide to achieve a more desirable degree of clarity. The factors and conditions of discoloration of the samples are described in Table 3. The bleaching operation was performed by placing sealed plastic bags containing the desired pulps and chemicals in a hot water bath. Dough refining was also performed according to T $248 \mathrm{sp}-00$ standard of TAPPI regulation. In fact, the refining of the pulp is done to increase the strength of the fibers. From each of the mentioned compounds according to the standard T $205 \mathrm{sp}-02$ TAPPI regulation for measuring optical properties, $60 \mathrm{~g}$ paper was made under standard conditions (temperature $23^{\circ} \mathrm{C}$ and relative humidity $50 \%$ ). The brightness values of the handmade papers were measured in three replications. 
Table 3

Factors and conditions of bleaching.

\begin{tabular}{|llll|}
\hline Material Type & Quantity (\%) & Conditions & Quantity \\
\hline Hydrogen peroxide & $1.5 \%$ & dry matter (\%) & 10 \\
\hline Sodium hydroxide & $1 \%$ & ${ }^{\circ} \mathrm{C}$ & $60-70^{\circ} \mathrm{C}$ \\
\hline Sodium silicate & $2 \%$ & time (min) & 60 \\
\hline DTPA & $0.2 \%$ & $\mathrm{PH}($ final) & $10-10.5$ \\
\hline & & Sample dry weight (g) & 50 \\
\hline
\end{tabular}

Due to the fact that papers are made from a variety of pulp and paper-making methods, from the wood of coniferous and deciduous species, and also imported long fiber pulp is added to improve the strength properties, which is a cost and a lot of environmental issues. Included, a more thorough examination was performed as to whether recycled magazine pulp could partially replace some of these first-hand materials. Therefore, using broadleaf pulp of Populous deltoides, cooking was done by CMP method using sodium sulfite cooking liquid and sodium carbonate. The CMP pulp was then bleached one step with $3 \%$ peroxide. Finally, one step of CMP pulp was prepared in order to reach a freeness about 300 . OMG recycled papers were deinked by flotation using sodium hydroxide (1\%), sodium silicate $(2 \%)$, hydrogen peroxide (1\%) and DTPA (1\%) and then bleached with hydrogen peroxide at $1 \%$. Finally, OMG pulp was mixed with CMP pulp and long fiber pulp with the percentages in Table 4.

Table 4

Percentages of mixture of OMG pulp and CMP pulp and long fiber.

\begin{tabular}{|llll|}
\hline Samples & first-hand (\%) & long fibers (\%) & recycled fibers (\%) \\
\hline Sample A & $100 \%$ first-hand & $0 \%$ long fibers & $0 \%$ OMG recycled fibers (first control sample) \\
\hline Sample B & $80 \%$ first-hand & $20 \%$ long fibers & $0 \%$ OMG recycled fibers (second control \\
\hline Sample C & $80 \%$ first-hand & $15 \%$ long fibers & $5 \%$ OMG recycled fibers \\
\hline Sample D & $80 \%$ first-hand & $10 \%$ long fibers & $10 \%$ OMG recycled fibers \\
\hline Sample E & $80 \%$ first-hand & $5 \%$ long fibers & $15 \%$ OMG recycled fibers \\
\hline Sample F & $80 \%$ first-hand & $0 \%$ long fibers & $20 \%$ OMG recycled fibers \\
\hline
\end{tabular}

Each of the above compounds, according to the standard T 205 sp-02 of TAPPI regulations, to measure the degree of brightness and mechanical properties of $60 \mathrm{~g}$ paper, under standard conditions (temperature $23^{\circ} \mathrm{C}$ and relative humidity 50 Percent) was made and then according to the information obtained from the mentioned experiments, the best test sample (the best combination of pulps) in terms of the sum of mechanical and optical properties was determined using normalization calculations. The data obtained from the experiments were analyzed by analysis of variance and the means were grouped by Duncan's test. 


\section{Results And Discussion}

The brightness values of the handmade papers were measured in three replications. Figure 1 shows the changes in the degree of clarity of waste magazine (OMG) papers that have not been deinked, deinked, and deinked-bleached. As can be seen in the figure, the brightness of OMG stained with hydrogen peroxide has the highest degree of brightness.

Due to the shape, the brightness of the waste magazine paper increases significantly after deinking and peroxide staining. The decolorized magazine paper, which has also been bleached, has the highest degree of clarity, which is why it performs well in the descaling and bleaching steps of the pulp. As can be seen in other studies, for example, Kapania et al. (2008) investigated the ability of deinked waste paper to be stained with hydrogen peroxide. To compare recycled magazine pulp with CMP pulp, Fig. 2 shows the degree of clarity of handmade papers made from different combinations of pulp. As shown in Fig. 2, the degree of brightness of pulp containing different percentages of deinked OMG is higher than that of the first control sample containing $100 \%$ of CMP pulp. But it is less than the second control sample which contains CMP and long fibers. But this difference is small, and the deinked OMG is much clearer than the imported long fiber pulp. The results of analysis of variance and Duncan test are shown in Tables 5 and 6.

Table 5

Results of analysis of variance of the degree of brightness of handmade papers.

\begin{tabular}{|llllll|}
\hline & $\begin{array}{l}\text { Total } \\
\text { squares }\end{array}$ & $\begin{array}{l}\text { degree of } \\
\text { freedom }\end{array}$ & $\begin{array}{l}\text { Mean of } \\
\text { squares }\end{array}$ & F & $\begin{array}{l}\text { Significant at the 5\% } \\
\text { level }\end{array}$ \\
\hline Sample & 129.960 & 5 & 25.992 & 37.167 & 0.000 \\
\hline & 13.351 & 1 & 13.351 & 19.091 & 0.001 \\
\hline Repeat & 8.392 & 12 & 29.152 & 41.686 & 0.000 \\
\hline sum & 116.609 & 4 & 0.699 & & \\
\hline
\end{tabular}


Table 6

Duncan test results values of degree of brightness of handmade papers.

\begin{tabular}{|c|c|c|c|c|c|c|c|}
\hline \multirow[t]{2}{*}{ Sample } & & \multirow[t]{2}{*}{ Repeat } & \multicolumn{5}{|l|}{ Group } \\
\hline & & & 1 & 2 & 3 & 4 & 5 \\
\hline \multirow[t]{6}{*}{ Duncan test } & A & 3 & 46.6967 & & & & \\
\hline & D & 3 & & 50.9133 & & & \\
\hline & $\mathrm{F}$ & 3 & & 51.7500 & 51.7500 & & \\
\hline & C & 3 & & & 52.9600 & 52.9600 & \\
\hline & $E$ & 3 & & & & 53.4633 & \\
\hline & B & 3 & & & & & 55.3200 \\
\hline Significant a & he & $\%$ level & 1.000 & 0.244 & 0.102 & 0.475 & 1.000 \\
\hline
\end{tabular}

The results of analysis of variance show that there is a significant difference between different samples of pulp at the level of $5 \%$. The results of Duncan test also show that the samples are placed in 5 different groups, with treatments $A$ and $B$ each in a separate group, treatments $D$ and $F$ in a group, and treatments $\mathrm{C}$ and $\mathrm{E}$ in a group. Take. So there is a significant difference between different treatments and treatment A (100\% CMP). In other words, the addition of de-inked OMG pulp significantly increases the degree of brightness compared to the first control sample. However, there is a significant difference between treatment B (80\% CMP and $20 \% \mathrm{LF}$ ) and other treatments, which indicates that the addition of deinked OMG significantly reduces the brightness compared to the second control sample. The decrease in brightness seems to be due to the chemical properties of the recycled fibers. Among the different treatments containing deinked OMG, treatment $\mathrm{E}$ (80\% CMP, 5\% LF and 15\% OMG) has a high degree of clarity compared to other treatments containing deinked OMG. Figure 3 shows the matte handmade papers made from different combinations of pulp.

As can be seen in the figure, the matte content of the pulp containing the different percentages of deinked magazine paper is greater than that of the control sample. Therefore, considering that one of the characteristics of printing paper is its opacity, it can be concluded that the addition of desiccated magazine paper in any proportion to the mixture of CMP paste and imported long fiber paste (by increasing matte) improves The quality of the printing paper is achieved. The highest opacity is related to $\mathrm{F}$ treatment ( $80 \%$ CMP and $20 \%$ recycled paper). The results of analysis of variance test show that due to the mixing of descale magazine paper with CMP pulp and imported long fiber paste, the opacity of handmade papers increases significantly.

\section{Conclusions}

The results of experiments showed that the use of hydrogen peroxide and peroxy derivatives in waste paper bleaching has led to an increase in brightness of several percent [4]. Paper made this way can be 
used to make papers that need more whiteness than resistance. For example, these papers can be used to produce newspaper paper for temporary use. Due to the fact that a large amount of pulp is used to produce newspaper paper, this way, countless trees can be cut down. At present, despite various activities to develop the cultivation of suitable fast-growing species such as poplar to supply the required raw material, the lack of suitable cellulosic raw materials is still a major problem in the wood and paper industries. Due to the limited level of forests in the north of the country and the increase of their destructive conditions in recent yr. it is not possible to supply all the required raw materials from these forests and therefore it is necessary to study different solutions to compensate for this shortage, and be used if they are technically and economically suitable. Using recycled paper to produce paper compared to virgin fibers saves $55 \%$ of water resources and $70 \%$ of energy consumption. Another $74 \%$ reduction in air pollutant emissions from sending paper to landfills or incineration is another benefit of recycling. Overall, recycling reduces costs while reducing emissions. Recycling reduces the utilization of trees and at the same time creates more employment than when the pulp is made directly from wood.

Given that the impact of the use of recycled fibers in the production of newsprint is generally positive, the technological issues of the use of this type of fiber should be carefully considered, which can be the subject of further research. Due to the scope of work, from pulp preparation to re-pulping, flotation, inkjet removal and making and testing of handmade papers, many factors were considered constant in the repulping and flotation stages. Therefore, in order to perform the next steps of the research, the following items are recommended:

1. Investigation of the role of physical and chemical factors such as pulp dryness, $\mathrm{pH}$ and surfactants in the deinking process. Investigation of the effect of hydrogen peroxide content and two factors of temperature and time on bleaching on the properties of deinked pulp. Investigation of the effect of refining and re-pulping on the strength properties of recycled fibers. Using different recycled papers such as newspaper and magazine paper and office waste paper and printed paper with computer printing machines and comparing the deinking ability of their printed papers with each other.

\section{Declarations}

\section{Availability of data and materials}

All data used in this article are consumables used for the thesis. The output of these materials is available to the public as qualitative information in this article. If you need details and output of laboratory tests, send a message to the author's email in this article.

\section{Competing interests}

There are no competing interests.

\section{Funding}

Has no Funding. 


\section{Authors' contributions}

There are no Authors' contributions in this article.

\section{Acknowledgements}

I consider it necessary to thank all the professors of the Department of Organic Chemistry of the Islamic Azad University, North Tehran Branch and the Department of Wood and Paper Industries of Natural Resources of Gorgan University. I would also like to thank my dissertation professor, Dr. Ali Ghasemian.

\section{Authors' information}

${ }^{1}$ Department of Chemistry from Islamic Azad University (Tehran North Branch) - Iran.

\section{References}

1. Akbarpour I, Resalati H, Saraiian AR. Investigation of waste paper deinking capability of waste newspaper. Quarterly Journal of Wood and Forest Science and Technology Research, Year 17, Issue $2 ; 2010$.

2. Ariaie monfared $\mathrm{MH}$, Resalati $\mathrm{H}$, Qasemian A. Enzymatic deinking of office waste paper in comparison with conventional chemical methods: Part One - Appearance and optical properties of paper pulp. Wood and forest science and technology research. Volume, 18 issues; 4 from page 59 to page; 2011.

3. Felgner BL. An Analysis of the Wash and Flotation Deinking Processes. Western Michigan University - Paper Engineering Senior Theses; 1989.

4. OBRADOVIC D, NARAYAN MISHRA L. MECHANICAL PROPERTIES OF RECYCLED PAPER AND CARDBOARD - The Journal of Engineering and Exact Sciences - jCEC, Vol. 06 N. 03; 2020.

5. Ferguson LD. Properties That Allow DIP to Be Used as a Hardwood Substitute. TAPPI Papermaking Conf.Canada.pp.611-622; 2000.

6. Kopania E, Stupinska H, Palenik J. Susceptibility of Deinked Waste Paper Mass to Peroxide Bleaching. FIBERS \& TEXTILES in Eastern Europe 2008, Vol. 16, No. 4(69) pp112-116; 2008.

7. Les1ie L, Turai K L, Mittal et al. DEINKING OF WASTEPAPER - AN OVERVIEW. (eds.), Solution Behavior of Surfactants @ Plenum Press, New York; 1982.

8. Mirshakraei, SA. (Translation). Waste Paper Recycling Guide, Tehran: Ayizh, Written by Kate Katie, David Gast. 140 pages: illustrated, table, diagram; 2001.

9. Pourmousa Sh. Effect of Dispersion and Flotation Sequence on Optical and Mechanical Properties of Deinked Computer Printout. Lignocellulose 5(2), 118-127; 2016.

10. Qasemian, A. Investigation of the use of decolorized pulp of newspaper and waste paper in the composition of domestic CMP pulp for the production of newsprint, PhD thesis, University of Tehran; 2003. 
11. Rahim Ebrahimi BM, Ismaili $\mathrm{H}$, Resalati H. An Overview of the Types of Waste Paper Decomposition Methods. Quarterly Journal of Studies in the World of Color, Fourth Year No. 2 (13th, Summer 2014). Page 13; 2014.

12. Sharifi Taskooh H, Hamzeh Y, Pourmousi Sh. Improving the appearance and strength characteristics of sanitary papers by optimizing the variables of the bleaching process of recycled deinked pulp (Case study of Latif Paper Products Company). Third National Conference of Student Scientific Associations of Agriculture and Natural Resources; 2015.

13. Narayan Panda S, Kumar Biswal S. De-Inking of ONP Paper by using Different Surfactants: In Dissolved Air Flotation Process. International Journal of Recent Technology and Engineering(IJRTE). ISSN: 2277-3878, Volume - 8 Issue - 5, January; 2020.

14. Husovska V. Investigation of Recycled Paper Deinking Mechanisms. Western Michigan University; 2013.

15. Tabarestani ZA. Production of newsprint using recycled fibers. - Mazandaran Wood and Paper Industries Research and Development Expert. Fourth Conference of Research and Development Centers of Industries and Mines; 2003.

\section{Figures}

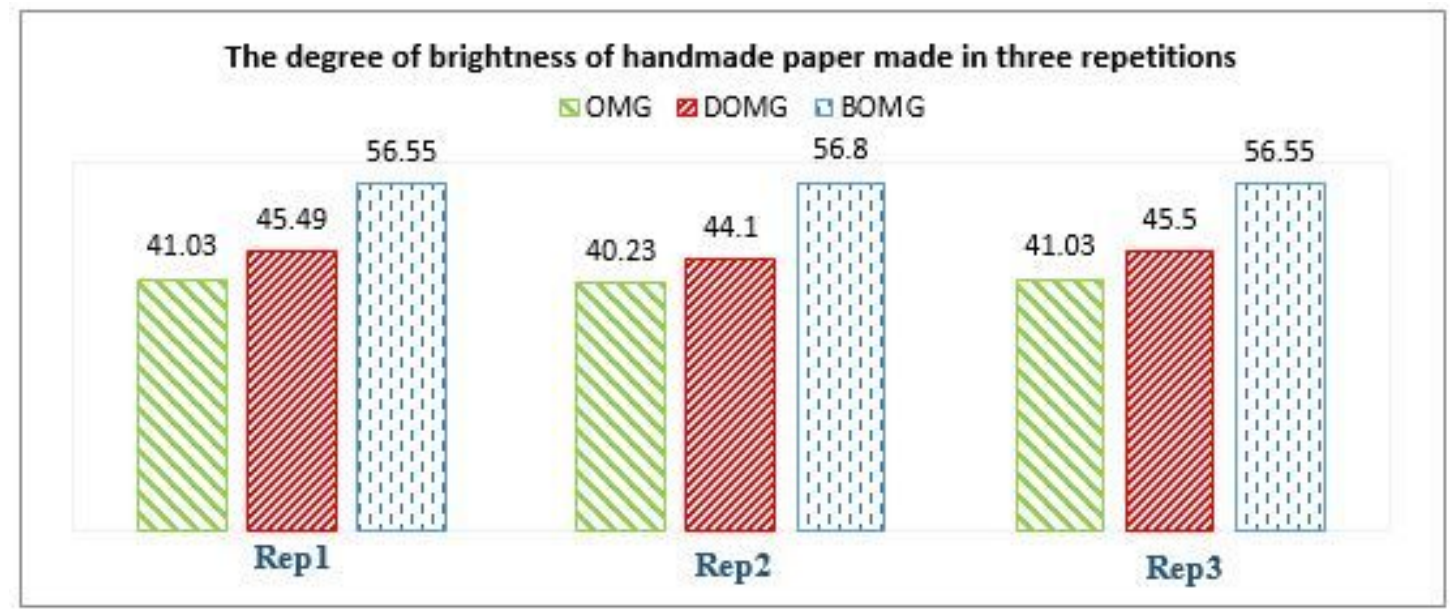

\section{Figure 1}

Increasing the brightness of OMG Pulp after descaling and bleaching. 


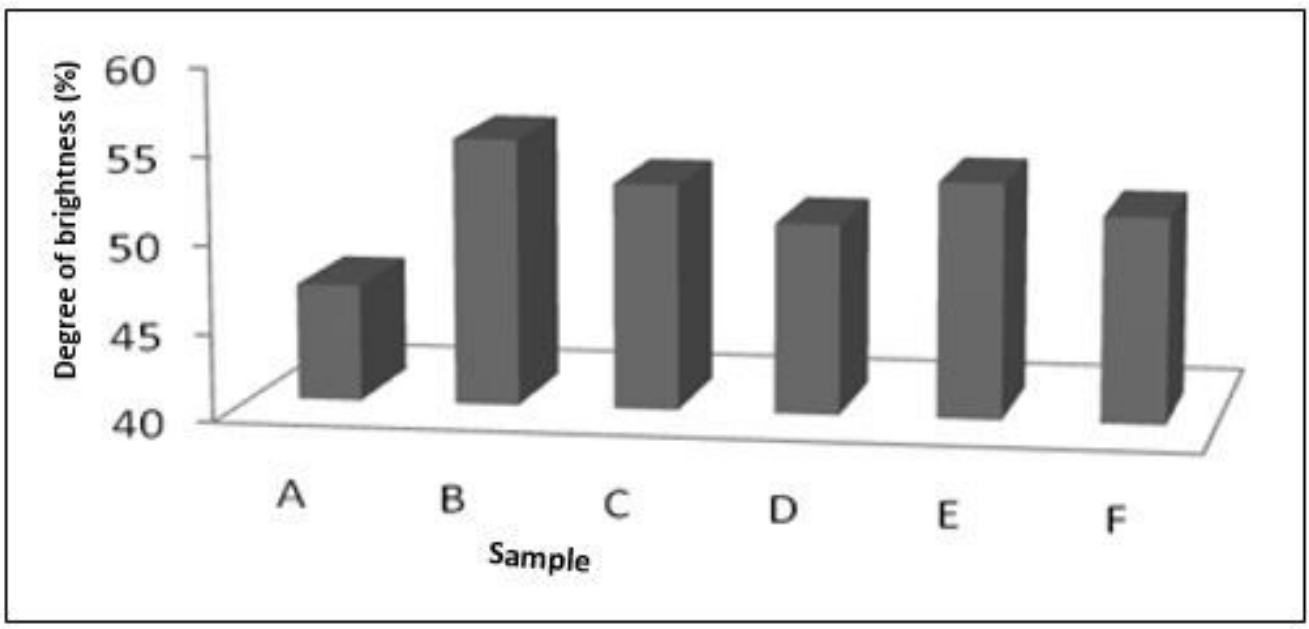

Figure 2

The effect of different percentages of mechanically deinked pulp of deltoid poplar on the gloss of handmade paper.

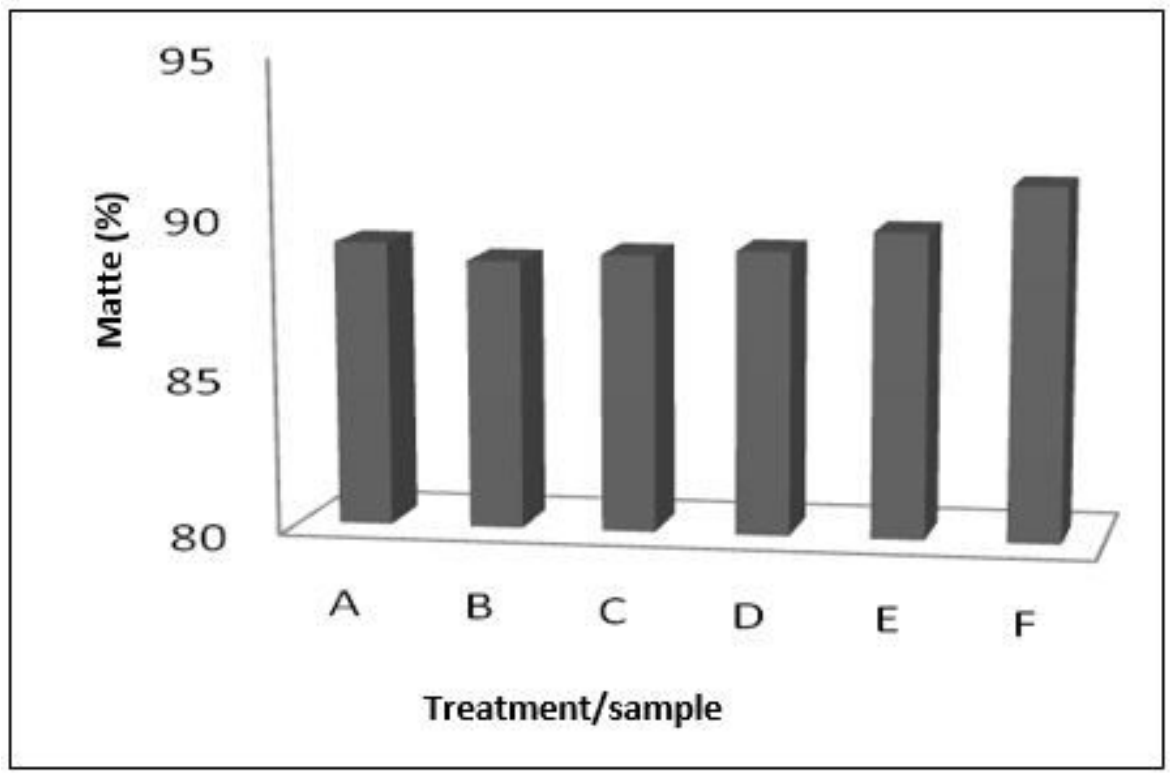

Figure 3

matte handmade papers made from different combinations of pulp. 